\title{
Exploring Puerto Rican Preservice Teachers' Resilience: A Focus Group Study
}

\author{
Yitza A. Arcelay-Rojas \\ Walden University
}

\begin{abstract}
This study explored the experiences of 10 Puerto Rican middle and high school preservice teachers at the end of their student teaching experience. The qualitative design, using the focus group technique, provided insight into the phenomenon of teachers' resilience. The analysis incorporated the main constructs of resilience-building proposed by Jordan's model of relational resilience: mutuality, empowerment, and development of courage. This study reinforced the notion of the importance of promoting supportive relationships with mentors and students. These relationships empowered teachers and helped them become more skilled in their profession. Addressing more aspects of resilience-building including before, during, and after their student teaching field experience could benefit preservice teachers in thriving in the profession induction process.
\end{abstract}

Keywords: resilience, relational resilience, student teacher, student teaching, field experiences, qualitative, preservice teachers, focus group, adversity, education, education preparation program

\section{Introduction}

The high attrition levels in the teaching profession have generated a bigger interest in understanding the factors that could promote teachers' resilience (Hong, 2012; Mansfield, Beltman, Broadley, \& Weatherby-Fell, 2016). The concept of resilience represents a contemporary paradigm that promotes the development of various protective factors that can promote the mental health of the human being and be a positive influence to reduce negative and increase positive outcomes of mental health and performance in the teaching profession (Cefai \& Cooper, 2008, Masten \& Tellegen, 2012; Truebridge, 2016). Accordingly, the strategies that foster resilience in individuals and environments have been studied as a way to increase positive outcomes in teachers (Clara, 2017; Le Cornu, 2009; Mansfield et al., 2016; Mansfield, Beltman \& Price, 2014; Thieman, Marx, \& Kitchel, 2014; Truebridge, 2016). Resilient teachers have the capacity to thrive amidst adversity, develop empathy and emotional intelligence, have effective skills in classroom management, and have a high sense of commitment to the profession (Hong, 2012; Howard \& Johnson, 2004).

Teachers face different challenging experiences depending on the phases of their professional careers (Day \& Gu, 2014). The purpose of this qualitative study was to explore the experiences of secondary level preservice teachers and their resilience during their student teaching experience. The participants were enrolled in the secondary-level education program student teaching experience at a university in Puerto Rico. The secondary level includes teachers who are preparing to teach in middle and high school. The student teaching field experience is college supervised and requires prospective educators to become immersed in teaching, thus having the responsibilities of a professional teacher.

The research questions guiding the study were aimed at understanding the experiences and the resilience characteristics the preservice teachers exhibited during student teaching. Three research questions (RQs) guided this study: 
Research Question 1 (RQ1): How do secondary-level Puerto Rican preservice teachers describe the support they received during their student teaching field experience?

Research Question 2 (RQ2): How do secondary-level Puerto Rican preservice teachers describe the qualities of resilience they perceive they possess?

Research Question 3 (RQ3): How do secondary-level Puerto Rican preservice teachers describe their experiences during their student teaching?

\section{The Concept of Resilience}

The concept of resilience emerged in the psychology field. Later, the term was adopted by the social sciences to describe the ability to overcome situations in a high-risk environment and develop into an emotionally and socially functional person (Munist et al., 1998). Masten, Best, and Garmezy (1990) defined resilience as "the process of, capacity for, or outcome of successful adaptation despite challenging or threatening circumstances" (p. 425). Later, Grotberg (1995) defined resilience as "the human capacity to face, overcome and be strengthened by or even transformed by the adversities of life" (p. 5). Two generations of research have shed light on the concept of resilience. The first generation can be located in the 1960s and the second generation in the mid-1990s (Garmezy \& Rutter, 1983; Rutter, 1979; Werner, 1992; Werner \& Smith, 1982, 1992). The first definitions include personal qualities such as autonomy and self-esteem that could help people overcome adversity (Masten \& Garmezy, 1985). Researchers such as Masten and Garmezy focused on the inclusion of factors external to the individual such as the socioeconomic level, the family structure, or the presence of a significant adult. Resilience factors were also organized into three categories: individual attributes, family traits, and the characteristics of the social environments in which people live (Luthar, Cicchetti \& Becker, 2000). In contrast, the second generation directed its attention toward the exploration of the processes associated with a positive adaptation of the person who has lived or lives in adversity. The researchers investigated the factors that helped individuals overcome the adversities and included an understanding of their interaction (Luthar, 2006).

\section{Relational Resilience}

Various protective factors are related to resilience (Cefai \& Cooper, 2008). Werner (1992) stated that the most important factor in building and promoting resilience is a supportive and caring relationship with significant others. The role of relationships in building and developing resilience in adversity has been established by other researchers as well (Benard, 2004; Henderson \& Milstein, 2003; Luthar, 2006, Obradović, 2012, Truebridge, 2016). Consistent, nurturing, and protective interactions can influence the stress response system and may contribute to a healthier reaction to external stressors (Gunnar \& Quevedo, 2007; Obradović, 2012).

This dynamic process of growth-fostering interrelationships and connectedness is also emphasized by Jordan (2006), who applied the relational-cultural theory to the resilience concept. As stated by Jordan (2017), the relational-cultural theory "is a theory about our basic interconnectedness, about the inevitability of needing one another throughout our lives" (p. 231), which resonates with the findings of studies on resilience. She proposed a model of relational resilience that identifies three main building blocks of this resilience: mutuality, empowerment, and development of courage. Mutuality refers to the impact of finding strong mutual, reciprocal, relationships (Jordan, 2017), and this is also at the core of resilience protective factors (Luthar, 2006). When these supportive and mutual relationships exist, the individual is empowered. In other words, the person becomes stronger and self-confident and exhibits the characteristics of the resilient person. Subsequently, the individual may also develop courage to successfully engage with challenging situations and continue being resilient (Jordan, 2017). 


\section{Characteristics of the Resilient Person}

The study of the concept of resilience has generated certain attributes that characterize a resilient person. Benard (2004) grouped these attributes into four components: (a) social competence, (b) problem solving, (c) autonomy, and (d) sense of purpose. The components, in turn, incorporated the seven characteristics of resilient people established by Wolin and Wolin (1993): (a) introspection, (b) independence, (c) ability to relate, (d) initiative, (e) humor, (f) creativity, and (g) morality. Social competence comprises relationships, and the characteristics related to this component include the ability to (a) elicit positive responses from others, (b) communicate and demonstrate affection and empathy, and (c) forgive and be compassionate and altruistic (Benard, 2004; Day \& Gu, 2014; Wolin \& Wolin, 1993). Problem solving includes skills such as (a) planning, (b) resourcefulness or the ability to know how to ask for help to use support resources, (c) critical thinking and the ability to create order from chaos and disorder, and (d) the ability to gain insight by transforming perceived reality (Benard, 2004; Hong, 2012; Wolin \& Wolin, 1993). The resilient person uses these skills to produce positive changes in frustrating situations.

As stated by Benard (2004), the autonomy component refers to the ability to act independently, and it is related to the individual's sense of positive identity. Likewise, autonomy is also developed thru adaptive distancing, in other words, the ability to distance the self from dysfunctional environments and not take responsibility for being the cause of that dysfunction. This includes the resistance to accepting negative messages about a person's identity or culture (Benard, 2004; Mansfield et al., 2016; Wolin \& Wolin, 1993). The feeling of self-control, personal power, initiative or inner drive, mindfulness, and sense of humor are part of this component, as well as individuals' capacity to manage their own emotions and impulses. Benard (2004) further explained that an important characteristic of autonomy is self-efficacy or individuals' ability to feel confident in their own power.

The fourth component, sense of purpose, is related to individuals' understanding and discovery of their own life meaning. It comprises characteristics such as being goal-oriented and motivated for achievement and having educational aspirations, optimism, persistence, hope, faith, spirituality, and a sense of meaning. These traits are related to the intentionality that people follow to achieve their objectives, the way they are motivated, and how they avoid feelings of hopelessness (Benard, 2004).

\section{Teacher Resilience}

As stated by Clara (2017), "teacher resilience happens when a teacher adapts positively to an adverse situation" (p. 82). Furthermore, Gu (2014) explained that teacher relational resilience is context specific, role specific, and related to the teacher's sense of commitment, equilibrium, and agency. It is context specific as it is related to the level of support the teacher receives from the school managers or leaders and the support and positive feedback received from parents and students. As Benard (2004) explained, social competence is an important component of the resilient person. In this regard, supportive relationships with mentors could promote the prospective teachers' resilience by encouraging them to thrive during the student teaching experience. It is role specific because it is closely associated with the teachers' commitment or a sense of vocational calling to the profession $(\mathrm{Gu}, 2017)$. This sense of purpose and commitment results from a reappraisal of their role in ways that allow them to be encouraged and strengthened to become resilient in their profession (Clara, 2017; Gu, 2017).

\section{Resilience and the Educator Preparation Program Curriculum}

Equally important and aligned to resilience building is that teacher education be responsive to and integrate mental health and resilience topics (Cefai \& Cavioni, 2014; Koller \& Bertel, 2006;

Mansfield et al., 2016). Koller and Bertel (2006) explained that the competencies of graduates should 
include an understanding of the following topics: (a) promotion of resilience, (b) what mental health is and what relevance it has at school, (c) the difference between mental health and mental illness, (d) the importance of emotional and social health, (e) the creation of an emotionally healthy classroom, (f) mental health interventions in schools, (g) prevention of school violence, (h) intervention of individual and group crises, and (i) well-being of teachers. These authors also suggested that psychology courses should incorporate the following topics: (a) how to create a positive school environment that promotes healthy psychological development for all students, (b) strategies of empowerment and collaboration with families so that they can promote adequate psychological development in their children, (c) how to make early interventions in cases of at-risk students, and (d) the adaptation of classroom instruction to meet the needs of those students who may develop or who have mental health problems.

Mansfield and colleagues (2016) also recommended including resilience topics in teacher education. The curriculum encompassed several components that should be taught including resilience building and relationships, well-being, motivations, and emotions. Mansfield et al. posited that prospective teachers should understand what resilience is and how to develop it. Teachers should also work on improving social competence and communication skills to establish effective relationships with students, parents, and colleagues. Other skills to be incorporated in teacher education that are related to resilience building included self-care and stress and emotions management (Mansfield et al., 2016). In general, Mansfield et al.'s study on understanding how prospective teachers become resilient can inform educator preparation programs (EPP) on how to develop a curriculum in which the concept of resilience is appropriately integrated and promoted not only in courses but as part of teaching field experiences (Thieman et al., 2014).

\section{Context}

The island of Puerto Rico is a territory of the United States, which is defined by the U.S. Department of the Interior (n.d.), as "an unincorporated United States insular area" (para. 8). The United States granted Puerto Ricans U.S. citizenship in 1917, and Puerto Rico's education system is very similar to the U.S. system. For example, the No Child Left Behind Act of 2001 also applied to the Puerto Rico educational system. The island has a K-12 school system divided into elementary and secondary, which includes middle and high school education. Also, the curriculum follows mostly the same subjects as in the United States and grading scales are also alike (Trines, 2018). Similar to what is happening in other states, the teachers living in the island are facing similar issues, and they also have protested and pushed for higher salaries and funding for public schools (Mazzei, 2018).

In addition, the education field is experiencing higher levels of attrition. In the year 2016, the most recent data available, Puerto Rico had an approximately $12 \%$ reduction in the teacher workforce compared to the academic year 2010 (Disdier-Flores \& Cruz-Soto, 2019). Likewise, between 2009 and 2017, teacher graduation dropped from 3,317 graduates to 1,583, a 52\% reduction (Consejo de Educación de Puerto Rico, 2018). Sutcher, Darling-Hammond, and Carver-Thomas (2016) recommended diverse practices to retain teachers, which included improved mentoring and induction programs and competitive salaries among other practices. They also recommended establishing teacher residency models that effectively prepare teachers to deal with the challenges they could face while serving in high-need schools. Therefore, understanding how teacher preparation programs can contribute to promote resilience in their graduates is a critical research focus. 


\section{Method}

\section{Design}

In this study, I sought to understand the participants' perceptions of resilience and experiences with resilience in the context of their student teaching. The purpose of the qualitative methodology is to describe, discover, and interpret the meaning of experiences (Creswell \& Poth, 2018; Merriam \& Tisdell, 2016). Therefore, the nature of the qualitative design allowed exploration and interpretation of the experiences of the participants regarding the phenomenon of resilience during their student teaching field experience. This design was appropriate because I intended to explore and describe the meaning of the phenomenon of resilience using the focus group interview technique.

To improve triangulation, the participants also completed a written self-reflection at the end of their participation in the focus group. The prompts for this reflection were (a) "I consider myself resilient because ...," (b) "For me, resilience is ...," and (c) "My role as a teacher is ..."

\section{Data Collection Technique}

Krueger and Casey (2014) explained that focus groups are used to explore the participants' perspectives or opinions on a given topic. The participants, who have certain characteristics in common, share their perspectives in a discussion in which a moderator facilitates the exchange of opinions, feelings, experiences, and attitudes toward a topic or phenomenon (Stewart \& Shamdasani, 2015). Stewart and Shamdasani recommended conducting at least two focus groups with a minimum of four participants (Krueger \& Casey, 2014). In this study, I moderated two focus groups with five participants in each session. The sessions lasted approximately $90 \mathrm{~min}$, as suggested by Stewart and Shamdasani (2015). I concentrated on the group interaction including its dynamics of forming consensus and interpreting their experiences. I also attempted to establish a relationship of mutual trust with the participants to encourage their candid reflection regarding additional aspects and common experiences of resilience during the student teaching experience. Follow-up questions also allowed for exploring the participants' opinions in more depth and facilitated an understanding of their perceptions on the topic. The interview questions emerged from the main constructs of Jordan's model of relational resilience and the characteristics of the resilient person proposed by Wolin and Wolin (1993) and Benard (2004). The main constructs of relational resilience are mutuality, empowerment, and development of courage. Mutuality refers to the relationships that support the student teachers' development and that help them to build and cultivate the resilient characteristics that helped them become empowered and courageous to tackle all the challenges they experienced during their student teaching experience. Table 1 presents the list of questions that guided the focus group interview and alignment with each construct of relational resilience. 
Table 1. Focus Group's Interview Questions

\begin{tabular}{ll}
\hline Category & \multicolumn{1}{c}{ Question } \\
\hline General background & "Why do you want to be a teacher? What is the teacher role?" \\
"What you know about the concept of resilience?" & "Please describe the support you received from (a) teachers, (b) \\
Mutuality & (e) principals." \\
& "Describe your student teaching experience." \\
& "Do you consider yourself resilient? Explain." \\
"How do you identify resilience in your students?" & "How do you feel now when giving classes, as your student \\
Development of courage & teaching is about to end?" \\
& "How have you addressed challenging situations during the \\
& student teaching experience?" \\
\hline
\end{tabular}

\section{Data Analysis}

I recorded and transcribed verbatim the focus group discussions immediately after each session. I assigned a pseudonym to each participant to ensure confidentiality. A qualitative data analysis consists of a process of reduction and synthesis that begins with the categorization of emergent themes and the consolidation of categories through the continuous comparison of common patterns (Merriam \& Tisdell, 2016). I created a spreadsheet in Microsoft Excel in which I copied all the answers of each group session organized under the main interview questions. Then, I classified the most frequent answers among the groups and identified main emergent themes and their frequency. Using the literature review and the concepts of mutuality, empowerment and courage established by Jordan (2017), I also determined patterns of opinions and organized the emergent themes in categories. Table 2 presents an alignment of the research questions and the iterative process of emergent themes and categories that followed from the data analysis.

Table 2. Emergent Themes Organized Into Categories and Subcategories for Analysis

\begin{tabular}{lcc}
\hline Research Question & Emergent Theme & Category \\
\hline 1. How do secondary-level Puerto Rican & Feedback & Mutuality \\
preservice teachers describe the support & Support from mentors & \\
they received during their student teaching & Student-teacher & \\
field experience? & relationship & \\
2. How do secondary-level Puerto Rican & Resilient qualities & Empowerment \\
preservice teachers describe the qualities of & Nonresilient & \\
resilience they perceive they possess? & Positive experiences & $\begin{array}{c}\text { Development } \\
\text { 3. How do secondary-level Puerto Rican }\end{array}$ \\
preservice teachers describe their & Challenging \\
experiences during their student teaching? & Experiences & \\
& Behavior management & \\
& Anxiety & \\
&
\end{tabular}




\section{Participants}

The group of preservice teachers attended a private university in Puerto Rico accredited by the Middle States Association of Colleges and Schools. The EPP is accredited by the Council for the Accreditation of Educator Preparation. I selected the campus because it had the highest percentage of graduates of education compared to other university campuses. Similarly, the participants enrolled in the student teaching also represented the varied secondary-level specializations including math, language arts, history, health, and sciences. This varied representation of cases concurred with the maximum variation strategy recommended by Merriam and Tisdell (2016) to promote a wide range of perspectives and opinions.

After receiving Institutional Review Board and the College of Education approval, I made an announcement extending an invitation to students to participate voluntarily. I selected the participants according to their specializations and their availability. I divided the participants $(N=$ $10)$ into two groups. Group $1(n=5)$ consisted of two men and three women, and Group $2(n=5)$ consisted of all women. The specializations at the secondary level were as follows: history, biology, chemistry, school health, language arts, Spanish, and arts. All students were culminating their student teaching field experience, and I conducted the focus groups during the last week of their field experience. Table 3 shows a description of the participants.

Table 3. Description of Participants in Each Focus Group

\begin{tabular}{lcc}
\hline $\begin{array}{l}\text { Participant } \\
\text { (Pseudonym) }\end{array}$ & Specialization & Gender \\
\hline Group 1 & History & $\mathrm{F}$ \\
Maria & Spanish & $\mathrm{F}$ \\
Kim & Arts & $\mathrm{F}$ \\
Cathy & Language arts & $\mathrm{M}$ \\
Luis & Language arts & $\mathrm{M}$ \\
Jose & & \\
Group 2 & Chemistry & $\mathrm{F}$ \\
Lisa & Biology & $\mathrm{F}$ \\
Rose & School health & $\mathrm{F}$ \\
Angie & Biology & $\mathrm{F}$ \\
Carol & Biology & $\mathrm{F}$ \\
Melissa & & \\
\hline
\end{tabular}

\section{Findings}

\section{Knowledge About Resilience}

When the participants were asked about their understanding of the concept of resilience, only five of them said they had an idea of its meaning, but their ideas were vague. One of the participants, Kim, said, "It was not discussed so much [in the seminar class]. From what I could understand, it is a capacity that the person has to face the difficulties, to cope with them in a different way." As moderator, I had to explain the concept in more depth. They revealed that they had not studied the concept in-depth in their courses, and they only recalled hearing of it in the seminar they took while registered in their student teaching field experience. After I explained the concept, they started to reflect on their own resilience characteristics and the relationships that fostered their resilience in life. At the end of the focus group session, they completed a self-reflection in which they contemplated their resilience. These prospective teachers considered themselves resilient because they thought themselves persistent, focused on their goals, having a positive mindset, and capable of 
feeling empathy. They had faced adversity in their personal lives and had thrived amidst coming from dysfunctional families, facing bullying, and experiencing sickness and other adversities.

Jordan (2006) identified three main aspects of resilience building and explained how effective relationships may empower teachers in their practice and encourage them to keep thriving: mutuality, empowerment, and development of courage. The Findings section includes three main categories based on these three main aspects of resilience described by Jordan. Each category aligns with the respective research questions. The first category, mutuality, aligned with RQ1; the second category, empowerment, related to RQ2; and the third category aligned with RQ3.

\section{Mutuality: Supportive and Reciprocal Relationships}

The participants described the significance of their relationship with mentors and students and how empowered they felt when these relationships were supportive and mutual. During the student teaching, the participants did not express a direct relationship with school principals and parents. As discussed by Rose, "My school is very big, and the director does not have much communication because she is almost never there, she has other activities." Instead, their most influential relationships for them were with the university supervisor, the cooperating teachers, and the students. The participants explained the importance of their mentors' positive feedback and support. In regard to the university supervisors, they expressed how important was their support. Similarly, they identified how influential were their cooperating teachers, both positively and negatively. For example, some participants expressed the mutual relationship that emerged with the cooperating teacher. Cathy said, "I also have received support from my cooperating teacher; she has helped me a lot, and the group has been very good with me." Rose expressed how fundamental was the support she received from the cooperating teacher and the university supervisor not only on the professional aspect:

During my student teaching, in the middle of the process, my husband lost his job and I did not have a job either. To buy the materials, to decorate the room, to make copies, even to pay for gas to go to the school, it was very difficult for me. And I was thinking to quit. I spoke with the cooperating teacher, and she said to me, "We are going to help you, don't quit, keep moving forward." With the support of the university supervisor and the cooperating teacher, I did it; I continued.

Others expressed mixed feelings regarding their relationship with their cooperating teachers. As described by Angie, "When I have my own classroom, I will do many other activities that my cooperating teacher didn't let me do. I understand her because she is retiring now." Luis added, "I also had problems with my cooperating teacher, because I don't discipline the students because they are noisy, I just tell them to lower their voice, but the cooperating teacher tell them to shut up or go to the office."

On the other hand, the relationship with students represented the core of the participants' experiences. As Maria described it, "What has kept me going since August are the students. I grew fond of them, I got used to them, and they to me." She also added,

Many people criticize me because I am studying for becoming a teacher, but really, I do not change it, because in the course of the student teaching, I experienced so much love for my students. I really do not regret it and becoming a teacher has been the best decision. 
Similarly, Kim also shared,

At first, I found it was difficult to gain rapport with the students. They did not accept that they had another teacher. They put a lot of resistance, but I incorporated fun activities, different games; I also tried not to be so rough, or so strict to getting closer to them. Today, I can tell you that I am doing very well with the students.

Comments like this one emerged in both groups and most of the participants agreed with that opinion. Although at the beginning it was difficult for the students to get used to a new teacher in the classroom, the teacher candidates could overcome the initial resistance and engage the students in their classroom. In general, the participants found mutual and supportive relationships during their student teaching field experience. These relationships were essential for students to thrive and for the student teachers to become more skilled in their profession.

\section{Empowerment: The Process of Becoming Stronger and Confident in Oneself}

The participants described the challenging situations they faced in their personal life and how these experiences helped them to develop empathy and a better understanding of factors that could be distressing their students. The participants spontaneously shared their personal experiences of adversity and how they managed to have a positive adaptation to problems. For example, Jose commented how he had the ability to recognize his potential despite being placed in a special education program while he was studying in the United States mainland. His first language is Spanish, and the school considered he had language problems. He reflected that he transformed his frustration into a reason to excel to show that he could succeed academically. In addition, he identified as a protective factor the influence of a teacher as an inspiring figure. He described his experience in the following way: "When I was in the United States, I was in special education, there was a teacher who believed in me and told me that I could give more, . . . it helped; he inspired me."

A second case that illustrated the characteristics of a resilient person was Carol. She indicated that despite coming from a home with domestic violence, she was always focused on her goals and how her religious values were a protective factor. As she explained, "Those [Christian] beliefs that I had, and that was what brought me afloat! If not, I consider that I, perhaps, had been out there in the street." She is an example of adaptive distancing because she was able to detach from the dysfunctional environment in which she was living. In addition, she explained that although she experienced adversity, she was not touched by those experiences and they helped her develop greater empathy toward her students. Teachers who cultivate these characteristics of resilience may also promote resilience in their students (Henderson \& Milstein, 2003; Truebridge, 2016)

Other participants reflected on their characteristics as resilient persons including social competence and sense of purpose. For instance, the resilience qualities that the participants expressed were based on having educational aspirations and a mentality directed toward reaching their goals. Both traits were manifested directly in the written document of reflective questions. For example, one of the participants stated, "I consider myself resilient because I have been determined to become a teacher amidst all the challenges." Similar comments emerged from both groups in which the participants reflected how being persistent helped them to advance to the final phase of their teaching preparation. Persistence, that is, moving forward and not surrendering, is a fundamental characteristic of resilient people (Morales, 2008). However, it is not the only characteristic that resilient people possess (Henderson, Benard, \& Sharp-Light, 2007).

Empathy was another resilience characteristic that several participants identified in themselves. Empathy is the ability to understand how others feel (Werner, 1992). This trait is part of emotional intelligence and is an essential personal skill that allows fostering of social affective development (Goleman, 1995). According to Benard (2004), empathy is a fundamental characteristic exhibited by 
resilient people. For example, Angie expressed how she developed empathy and cared for her students,

I have a student who had failed in several years and was very quiet. He was the most rejected. Maybe, I thought, it was because of his age that they rejected him, then I realized he was the quietest in the class. But when he approached me, I kept saying to him: "You can do it! You see that you can do it!" And from there, he continued improving in the class.

Luis also added how he also was able to empathize with his students,

I have been able to walk during recess with a student, because I see him with a face of tragedy, and I tell him, "What's the matter with you?" The student told me, "I'm tired of school, they give me a lot of homework." I also tell them, "If you want to be someone in life, you have to study, it's not easy." Each child is a different world, and everyone has their problems, their needs, differences. I identify myself with them, these kids are going through the same things that happened to me.

Benard stated how teachers who exhibit empathy can constitute a protective factor that promotes resilience if they care about the students achieving their greatest academic and social potential. Consistent with this approach, Carol explained, "That's why when students talk to me about their personal problems, as I went through and experienced that experiences as well, it is easier for me to be able to talk to them and understand them." Lisa shared that she also came from a dysfunctional home, and she described how she could understand students in a similar situation, "In my home too, I come from a dysfunctional home ... my father is an alcoholic. One puts oneself in the student's feet, because all of those influences it is not easy for them to concentrate."

Wolin and Wolin (1993) specified that another trait of the resilient teacher is developing problemsolving skills that include planning skills, self-efficacy, and the ability to create order from disorder. In particular, Group 2 participants agreed on how important it was for them to plan effectively. As Carol stated,

Planning is very important; in fact, without it, you don't know what you are going to give in class, the activities you are going to give, you don't know how long you will be with those students in that activity. It is a requirement, it is necessary for you to be able to give your class, you are guided by it ... as a teacher we cannot go there to improvise the class.

However, two participants from Group 1 stated that at the beginning of the student teaching field experience it was difficult to draft the teaching plans. All talked about that, at first, they were afraid of the reaction of the students and questioned their ability to create order in the classroom. For example, Jose said,

I was blocked with planning because I started with the objective, and then I looked for the standard. She [the cooperating teacher] told me, "First look for the standard, then the objective, so that you know the skills you are going to teach."

Another participant, Luis, recalled, “The first weeks were horrible, I didn't have time to do everything I planned. Now, I do everything on time. I take long hours planning, but the classes are totally different now." These comments reflect how these two candidates presented weaknesses in aspects of planning at the beginning, but with persistence and support from their cooperating teachers, they were able to refine their planning skills, which allowed them to integrate systematic actions aligned with expectations, goals, and specific objectives. 
Similarly, another aspect related to problem solving skills is creating order. These preservice teachers also discussed how they felt at the beginning of the student teaching experience. They all agreed that they felt anxiety and nervousness, especially in engaging students and promoting order in the classroom. Luis also shared how difficult it was to communicate effectively and maintain order in the classroom.

I put them to work in groups of four and that was a total chaos. For them it was a time for socializing. I was supposed to give them the instructions before I met them in a group, and I did it later. I had one student who asked me five times, "what do I do?" I explained like five times more, and he said, "I still don't understand," and I lost my patience, and I said, "You know what, ask one of your classmates." I lost my patience.

Problem solving skills are essential to produce positive changes in these kinds of frustrating situations. The participants described how during their student teaching field experience they improved these skills and started to meet these challenges effectively. At the end of their student teaching experience, they felt confidence in their problem-solving abilities, and they reiterated their calling to the profession.

\section{Development of Courage: Meeting Challenges With Resilience}

The preservice teachers described their perceived role as a teacher and identified a multiplicity of roles. While they recognized how overwhelming these roles could be, they also reiterated their vocation and commitment to the profession as expressing a sense of empowerment. Vocation is defined by Buijs (2005) as "a calling in life that consists of distinctive roles or functions" (p. 334). As expressed by Lisa, "I like education, I think we can contribute a lot to society from there. I like to work with young people, they are the future." This sense of calling to serve was expressed by all participants. They also attributed to this vocation their commitment to thrive during the student teaching field experience while experiencing a reality check with some aspects of the profession. As Angie described it, "I think teaching is a vocation, it comes out of instinct too; we arrive at school and we do not realize that we are doing it because it is a calling." This vocation is related to the traits of resilient persons who describe a sense a purpose in their lives (Clara, 2017; Gu, 2017; Wolin \& Wolin, 1993).

Although most of the participants described challenging situations related to their personal life and their student teaching experience, they were able to overcome the adversity. These adversities were related to the context and to their role. In terms of context, they had to deal with limited resources for their job and personal situations such as sickness and depression. In terms of their role, they had to overcome their anxiety generated by the student teaching experience related to planning and behavior management. At the end of their EPP, they showed how their resilience was built. As Melissa shared,

I liked this student teaching experience a lot. I had the opportunity to work, in this case with young people ... and as my peers shared, there are gratifying moments . . it is an experience of multiple experiences.

The participants agreed with these comments and also described their student teaching experience as successful. As Jose reflected, "I have grown a lot. The students respect me, talk to me, trust me, I have earned their trust, and I thought it would be harder. I have done well!"

In contrast, one participant pointed out that she did not consider herself a resilient person. Maria candidly shared, 
I do not consider myself very resilient. I have had many problems, and many people tell me that I used to be very happy. I feel trapped in the same problems, and it is very difficult for me to clear my mind.

This type of comment may reflect the need for support and emotional help that preservice teachers may have. When educational programs incorporate resilience-promoting strategies in a comprehensive manner, they can discover, address, and refer situations regarding the preservice teachers' emotional problems as well (Benard, 2004; Mansfield et al., 2016).

\section{Discussion}

The positive supportive relationships that emerged from the student teaching practice and the participants' vocation seemed to provide encouragement to them to continue in the field. This study reinforced the notion of the importance of supportive relationships and mutuality as the main factor of resilience building (Gu, 2014; Jordan, 2017). The participant relationship with cooperating teachers, university supervisors, and students constituted a significant factor in the participants' process of developing their resilience. However, because most of them didn't have, during the student teaching experience, a significant relationship with the school principals and parents, they could not describe it as influential to them as the relationship they established with university supervisors, cooperating teachers and students.

The positive feedback the preservice teachers received helped them through their teaching field experience and encouraged them to face the challenges of teaching with confidence in themselves. As described by other studies, feedback is essential and valuable for preservice teachers because it contributes to increasing their level of confidence and self-efficacy which at the same time are part of the characteristics of the resilient person (Fives, Hamman \& Olivarez, 2007; Hamman et al., 2006; Martins, Costa \& Onofre, 2015; Thurlings, Vermeulen, Bastiaens, \& Stijnen, 2013). In addition to valuing feedback, the student teachers also appreciated when cooperating teachers were positive role models. They explained that cooperating teachers who also were creative, updated in terms of teaching methods, caring and supportive, not only with them but also with their students, helped them to increase their confidence and empowerment. This created an atmosphere of learning and mutual support that fortified the preservice teachers' resilience.

Relationships with students were at the center of their perseverance and growth. As described by Jordan (2017), growth fostering relationships are characterized by empathy. The participants expressed their empathy to their students and the positive response they had from them as well. This mutuality with their students grew with time, and all participants described how it encouraged them to keep improving their teaching skills and become resilient. Likewise, this group of student teachers agreed that they all felt a deeply held desire to serve others. As Jordan (2006) stated, "a person's engagement in mutually empathic and responsive relationships" (p. 80) are a fundamental source of resilience.

All participants identified challenging situations during their student teaching experience and how they approached them. The types of challenging experiences described by these preservice teachers ranged from the lack of confidence in planning and behavior management to trying to manage multiple tasks and roles at the same time. However, they made an appraisal of the challenging situations they encountered and expressed how they learned from them. These situations helped them in understanding the reality of the profession and developing commitment and courage. This is particularly important in the development of resilience. When teachers can reappraise situations of adversity in ways that strengthen their vocation and commitment, they are becoming resilient (Clara, 2017; Kim \& Cho, 2012). 
The participants described how their own resilient characteristics helped them to develop the courage to address the challenges they encountered during their student teaching field experience. Also, they reflected upon other resilience characteristics that they still need to develop to feel confident and empowered in their teaching. They described several characteristics of a resilient person and candidly shared personal experiences that showcased their social competence, problem solving, autonomy, and sense of purpose. Personal strengths in social competence included empathy, caring, and compassion. In contrast, some weaknesses were shown in characteristics such as demonstrating effective communication. In regard to problem solving, the student teachers described their ability of critical thinking and insight; however, the most common weakness for these participants was their skills at behavior management. In terms of autonomy, some of the participants discussed their ability of adaptive distancing. They agreed that this ability has helped them in their lives to resist the negative or disempowering messages generated by others and develop courage to keep moving forward toward their goals. Henderson et al. (2007) also found that spirituality and being goal oriented are characteristics of a resilient person. Many of the preservice teachers in this study expressed how having educational goals and aspirations, faith, and spirituality have been essential in their resilience.

Although the student teachers identified characteristics of resilience in themselves, they agreed that more is needed in terms of the understanding of the concept of resilience. In terms of knowledge, the student teachers expressed that they would like to understand how resilience is built in themselves and their students. Likewise, they agreed that they would like to reflect on it and discuss it as part of their EPP courses as well. Likewise, they also expressed a need for emotional support during the intense stage of student teaching. This finding suggests that it is necessary to incorporate more topics related to resilience development throughout the EPP curriculum. A fleeting mention of the concept in one course is not enough for gaining an understanding on how to build resilience in their students and in themselves (Mansfield et al., 2016).

\section{Conclusions and Implications for Practice}

In this study, I explored the lived experiences of 10 secondary level teacher candidates at the end of their student teaching experience. It was evident these prospective teachers had a sense of caring and empathy for their students, and they showed many resilience characteristics through their perseverance in life and in college. This group of Puerto Rican preservice teachers could be more supported in the profession if they receive specific preparation on resilience starting in their EPP. Besides, teaching in Puerto Rico is a challenging task, and low salaries and lack of resources jeopardize the teacher's commitment. However, this does not mean they lose their vocation. A strong student teaching field experience with mentoring can increase preservice teachers' retention and slow turnover rates (Sutcher et al. 2016; Wright, Balgopal, Sample McMeeking, \& Weinberg, 2019).

In this study, the participants expressed the need for resilience training during their field experiences. Three essential skill-building areas emerged as essential aspects that the EPP should emphasize in its curriculum as well. These skills include problem-solving, social, and emotional competence. Incorporating and analyzing case studies and real-life scenarios using videos at different points of the EPP could also be helpful in connecting the preservice teachers to practical examples where they could be exposed to challenging situations or environments that could help them practice coping skills and develop resilience (Mansfield et al., 2016). Implementing support groups at the beginning, during, and at the end of the teaching field experiences could promote resilience by reducing the stress levels caused by the student teaching experience (Brigido, Borrachero, Bermejo, \& Mellado, 2013). At the same time, it would be necessary to revise the mentors' training to include a comprehensive curriculum that addresses resilience related topics including the importance of establishing an atmosphere of mutual support with student teachers. 
Chronic stress is related to profession fatigue and lead to the development of anxiety and other mental health problems. Resilience is an important skill that can be built to help counter chronic stress and support the teachers' well-being. That is why the topic of well-being needs to be included as part as any program that also is aimed at promoting both personal and professional resilience (Cheshire et al., 2017). A multilevel and relational resilience approach could help buffer the stress experienced in a profession shown to be highly distressful (Sela \& Harel, 2019). Understanding the lived experiences of Puerto Rican preservice teachers may help the EPP to listen the voices of these teachers. It is essential to recognize that promoting a better sense of connectedness through mutual relationships with colleagues and students could strengthen them and the profession overall.

The findings of this study are limited to preservice teachers who participated in it and only allow for conclusions applicable to them. Further research is necessary to explore how Puerto Rican novice teachers build their resilience. Future research could focus on including how the perceptions of resilience change related to context and years of experience in the field. Follow-up interviews could help in exploring how teachers' resilience is built over time and how relationships developed with colleagues influence it.

\section{References}

Benard, B. (2004). Resiliency: What we have learned. San Francisco, CA: WestEd.

Brigido, M., Borrachero, A. B., Bermejo, M. L., \& Mellado, V. (2013). Prospective primary teachers' self-efficacy and emotions in science teaching. European Journal of Teacher Education, 36, 200-217. doi:10.1080/02619768.2012.686993

Buijs, J. A. (2005). Teaching: Profession or vocation? Journal of Catholic Education, 8, 326-345. doi:10.15365/joce.0803042013

Cefai, C., \& Cavioni, V. (2014). From neurasthenia to eudaimonia: Teachers' well-being and resilience. In C. Cefai \& V. Cavioni (Eds.), Social and emotional education in primary school: Integrating theory and research into practice (pp. 133-148). New York, NY: Springer Science Business Media.

Cefai, C., \& Cooper, P. (2008). Promoting resilience in the classroom: A guide to developing pupils' emotional and cognitive skills. London, United Kingdom: Jessica Kingsley.

Cheshire, A., Hughes, J., Lewith, G., Panagioti, M., Peters, D., Simon, C., \& Ridge, D. (2017). GPs' perceptions of resilience training: A qualitative study. British Journal of General Practice, 67, e709-e715. doi:10.3399/bjgp17X692561

Clara, M. (2017). Teacher resilience and meaning transformation: How teachers reappraise situations of adversity. Teacher and Teacher Education, 63, 82-91.

doi:10.1016/j.tate.2016.12.010

Consejo de Educación de Puerto Rico. (2018). Compendio estadístico de la educación superior (IPEDS). Retrieved from https://estadisticas.pr/en/inventario-de-estadisticas/integratedpostsecundary-education-data-system-ipeds

Creswell, J. W., \& Poth, C. N. (2018). Qualitative inquiry and research design: Choosing among five approaches (4th ed.). Thousand Oaks, CA: Sage.

Day, C., \& Gu, Q. (2014). Resilient teachers, resilient schools: Building and sustaining quality in testing times. New York, NY: Routledge.

Disdier-Flores, O. M., \& Cruz-Soto, L. J. (2019). Anuario estadístico del sistema educativo 2016. Retrieved from https://estadisticas.pr/files/Comunicados/Anuario\%20Estadistico\%20del\%20Sistema\%20Educ ativo\%202015-2016.pdf 
Fives, H., Hamman, D., \& Olivarez, A. (2007). Does burnout begin during student teaching? Analyzing efficacy, burnout, and support during the student teaching semester. Teaching and Teacher Education, 23, 916-934. doi:10.1016/j.tate.2006.03.013

Garmezy, N., \& Rutter, M. (Eds.). (1983). Stress, coping, and development in children. New York, NY: McGraw-Hill.

Goleman, D. (1995). Emotional intelligence. New York, NY: Bantam.

Grotberg, E. (1995). A guide to promoting resilience in children: Strengthening the human spirit. Retrieved from https://bibalex.org/baifa/Attachment/Documents/115519.pdf

$\mathrm{Gu}, \mathrm{Q}$. (2014). The role of relational resilience in teachers' career-long commitment and effectiveness. Teachers and Teaching, 20, 502-529. doi:10.1080/13540602.2014.937961

Gu, Q. (2017). Resilient teachers, resilient schools: Building and sustaining quality in testing times. In X. Zhu, A. L. Goodwin, \& H. Zhang (Eds.), Quality of teacher education and learning: Theory and practice (pp. 119-144). Singapore, Singapore: Springer.

Gunnar, M., \& Quevedo, K. (2007). The neurobiology of stress and development. Annual Review of Psychology, 58, 145-173. doi:10.1146/annurev.psych.58.110405.085605

Hamman, D., Olivarez, A., Lesley, M., Button, K., Chan, Y., Griffith, R., \& Elliot, S. (2006). Pedagogical influence of interaction with cooperating teachers on the efficacy beliefs of student teachers. Teacher Educator, 42, 15-29. doi:10.1080/08878730609555391

Henderson, N., Benard, B., \& Sharp-Light, N. (2007). Resiliency in action: Practical ideas for overcoming risks and building strengths in youth, families, and communities. Ojai, CA: Resiliency in Action.

Henderson, N., \& Milstein, M. (2003). Resiliency in schools: Making it happen for students and teachers. Thousand Oaks, CA: Corwin Press.

Hong, J. Y. (2012). Why do some beginning teachers leave the school, and others stay? Understanding teacher resilience through psychological lenses. Teachers and Teaching, 18, 417-440. doi:10.1080/13540602.2012.696044

Howard, S., \& Johnson, B. (2004). Resilient teachers: Resisting stress and burnout. Social Psychology of Education, 7, 399-420. doi:10.1007/s11218-004-0975-0

Jordan, J. V. (2006). Relational resilience in girls. In S. Goldstein \& R. Brooks (Eds.), Handbook of resilience in children (pp. 79-90). New York, NY: Springer.

Jordan, J. V. (2017). Relational-cultural theory: The power of connection to transform our lives. Journal of Humanistic Counseling, 56, 228-243. doi:10.1002/johc.12055

Kim, H., \& Cho, Y. (2012). Pre-service teachers' motivation, sense of teaching efficacy, and expectation of reality shock. Asia-Pacific Journal of Teacher Education, 42, 67-81. doi:10.1080/1359866X.2013.855999

Koller, J., \& Bertel, J. (2006). Responding to today's mental Health needs of children, families and schools: revisiting the preservice training and preparation of school-based personnel.

Education and Treatment of Children, 29, 197-217. Retrieved from https://search-ebscohostcom.ezp.waldenulibrary.org/login.aspx?direct=true\&db=edsgea\&AN=edsgcl.149622755\&site $=$ eds-live $\&$ scope $=$ site

Krueger, R., \& Casey, M. (2014). Focus groups: A practical guide for applied research (5th ed.). Thousand Oaks, CA: Sage.

Le Cornu, R. (2009). Building resilience in pre-service teachers. Teaching and Teacher Education, 25, 717-723. doi:10.1016/j.tate.2008.11.016 
Luthar, S. S. (2006). Resilience in development: A synthesis of research across five decades. In D. Cicchetti \& D. J. Cohen (Eds.), Developmental psychopathology: Risk, disorder, and adaptation (2nd ed., pp. 739-795). New York, NY: Wiley.

Luthar, S. S., Cicchetti, D., \& Becker, B. (2000). The construct of resilience: A critical evaluation and guidelines for future work. Child Development, 71, 543-562. doi:10.1111/1467-8624.00164

Mansfield, C. F., Beltman, S., Broadley, T., \& Weatherby-Fell, N. (2016). Building resilience in teacher education: An evidenced informed framework. Teachers and Teaching, 54, 77-87. doi:10.1016/j.tate.2015.11.016

Mansfield, C. F., Beltman, S., \& Price, A. (2014). "I'm coming back again!": The resilience process of early career teachers. Teachers and Teaching, 20, 547-567. doi:10.1080/13540602.2014.937958.

Martins, M., Costa, J., \& Onofre, M. (2015). Practicum experiences as sources of pre-service teachers' self-efficacy. European Journal of Teacher Education, 38, 263-279. doi:10.1080/02619768.2014.968705

Masten, A., Best, K., \& Garmezy, N. (1990). Resilience and development: Contributions from the study of children who overcome adversity. Development and Psychopathology, 2, 425-444. doi:10.1017/S0954579400005812

Masten, A., \& Garmezy, N. (1985). Risk, vulnerability, and protective factors in developmental psychopathology. In B. Lahey \& A. Kazdin (Eds.), Advances in clinical child psychology (pp. 1-52). New York, NY: Plenum Press.

Masten, A., \& Tellegen, A. (2012). Resilience in developmental psychopathology: Contributions of the project competence longitudinal study. Development and Psychopathology, 24, 345-361. doi:10.1017/S095457941200003X

Mazzei, P. (2018). Puerto Rico's schools are in tumult, and not just because of Hurricane Maria. Retrieved from https://www.nytimes.com/2018/06/01/us/puerto-rico-school-closings.html

Merriam, S. B., \& Tisdell, E. J. (2016). Qualitative research: A guide to design and implementation. (4th ed.). San Francisco, CA: Jossey Bass.

Morales, E. (2008). Academic resilience in retrospect: Following up a decade later. Journal of Hispanic Higher Education, 7, 228-248. doi:10.1177/1538192708317119

Munist, M., Santos, H., Kotliarenco, M. A., Suarez-Ojeda, E. N., Infante, F., \& Grotberg, E. (1998). Manual de promoción e identificación de la resiliencia en niños y adolescentes. Washington, DC: Organización Panamericana de la Salud y Organización Mundial de la Salud. Retrieved from http://www.paho.org/spanish/hpp/hpf/adol/Resilman.pdf

No Child Left Behind Act of 2001, Pub. L. 107-110, 20 U.S.C. $§ 6319$ (2002).

Obradović, J. (2012). How can the study of physiological reactivity contribute to our understanding of adversity and resilience processes in development? Development and Psychopathology, 24, 371-387. doi:10.1017/S0954579412000053

Rutter, M. (1979). Protective factors in children's responses to stress and disadvantages. Annals of the Academy of Medicine, Singapore, 8, 324-338. Retrieved from https://www.ncbi.nlm.nih.gov/pubmed/547874

Sela, O., \& Harel, M. (2019). You have to prove yourself, initiate projects, be active: The role of novice teachers in their own induction process. Professional Development in Education, 45, 190. doi:10.1080/19415257.2018.1441173

Stewart, D., \& Shamdasani, P. (2015). Focus groups: Theory and practice (3rd ed.). Thousand Oaks, CA: Sage. 
Sutcher, L., Darling-Hammond, L., \& Carver-Thomas, D. (2016). A coming crisis in teaching? Teacher supply, demand, and shortages in the U.S. Palo Alto, CA: Learning Policy Institute. Retrieved from https://learningpolicyinstitute.org/product/coming-crisis-teaching

Thieman, E. B., Marx, A. A., \& Kitchel, T. (2014). "You've always got challenges": Resilience and the preservice teacher. Journal of Agricultural Education, 55, 12-23. doi:10.5032/jae.2014.04

Thurlings, M. M., Vermeulen, M. M., Bastiaens, T. T., \& Stijnen, S. S. (2013). Understanding feedback: A learning theory perspective. Educational Research Review, 9, 1-15. doi:10.1016/j.edurev.2012.11.004

Trines, S. (2018). Economic storm: The crisis of education in Puerto Rico. Retrieved from https://wenr.wes.org/2018/05/economic-storm-the-crisis-of-education-in-puerto-rico

Truebridge, S. (2016). Resilience: It begins with beliefs. Kappa Delta Pi Record, 52, 22-27. doi:10.1080/00228958.2016.1123041

U.S. Department of the Interior. (n.d.). Definitions of insular area political organizations. Retrieved from https://www.doi.gov/oia/islands/politicatypes

Werner, E. E. (1992). The children of Kauai: Resiliency and recovery in adolescence and adulthood. Journal of Adolescent Health, 13, 162-268. doi:10.1016/1054-139X(92)90157-7

Werner, E. E., \& Smith, R. S. (1982). Vulnerable but invincible: A study of resilient children. New York, NY: McGraw-Hill.

Werner, E. E., \& Smith, R. S. (1992). Overcoming the odds: High-risk children from birth to adulthood. Ithaca, NY: Cornell University Press.

Wolin, S., \& Wolin, S. (1993). The resilient self: How survivors of troubled families rise above adversity. New York, NY: Villard Books.

Wright, D. S., Balgopal, M. M., Sample McMeeking, L. B., \& Weinberg, A. E. (2019). Developing resilient K-12 STEM teachers. Advances in Developing Human Resources, 21, 16. doi:10.1177/1523422318814483

The Journal of Educational Research and Practice provides a forum for studies and dialogue that allows readers to better develop social change in the field of education and learning. Journal content may focus on educational issues of all ages and in all settings. It also presents peer-reviewed commentaries, book reviews, interviews of prominent individuals, and additional content. The objectives: We publish research and related content that examines current relevant educational issues and processes aimed at presenting readers with knowledge and showing how that knowledge can be used to impact social change in educational or learning environments. Additional content provides an opportunity for scholarly and professional dialogue regarding that content's usefulness in expanding the body of scholarly knowledge and increasing readers' effectiveness as educators. The journal also focuses on facilitating the activities of both researcher-practitioners and practitioner-researchers, providing optimal opportunities for interdisciplinary and collaborative thought through blogging and other communications. Walden University Publishing:

http://www.publishing.waldenu.edu 